\title{
Espécies ameaçadas de extinção na Amazônia
}

O que são as espécies ameaçadas de extinção na Amazônia e o que elas representam?

É uma pergunta bastante simples, mas nada fácil de responder, pois o nosso conhecimento da fauna e flora da vasta região florestada, que cobre 500.000 .000 hectares do território nacional e mais 300.000 .000 hectares distribuídos entre Bolívia, Colômbia, Equador, Peru e Venezuela, é largamente incompleto. Abençoado com clima ameno ao desenvolvimento da vida, não existe lugar no mundo onde a natureza floresça com mais exuberância. Apesar de pequenas equipes de cientistas e técnicos nacionais e estrangeiros pesquisando a riqueza biológica da região, a imensidão da Amazônia confunde a imaginação e frustra esforços para seu conhecimento.

\section{Quantas espécies a região abriga}

Calcula-se que no mundo inteiro existem entre três e dez milhões de espécies de seres vivos ${ }^{1}$, das quais aproximadamente $10 \%$ são plantas, e as demais, $90 \%$ animais. A diferença entre estes dois números élúcida reflexão do quadro de nossa ignorância de nossos "companheiros de viagem" no planeta, principalmente das regiões tropicais. Dada esta pobreza de informações, como nós podemos desvendar a importância da Amazônia relativa às outras partes do mundo em termos de sua riqueza biológica? Calcula-se que $75 \%$ de todos os animais são insetos ${ }^{2}$, mas este grupo é tão pouco conhecido que pelo menos a metade das espécies de insetos da Amazônia não tem sequer nome científico. De todos, o grupo melhor conhecido é o das aves, que pode ser usado para se fazer um rude cálculo. Amadon $^{3}$ assinalou 592 espécies de aves para a Flo- resta Amazônica, contando somente aquelas espécies que têm como seu habitat a floresta densa. Se acrescentarmos as espécies da Amazônia que vivem nas várzeas, campos naturais, campinas e outras vegetações abertas da região, chegaremos a um número de aproximadamente novecentas espécies para a avifauna da Amazônia.

Sabemos que no mundo inteiro existem pouco mais de nove mil espécies de aves ${ }^{4}$. Julgando que as aves são representativas, podemos, então, dizer que aproximadamente $10 \%$ de todas as espécies existentes no mundo se encontram na Amazônia. Ou, melhor, podemos dizer que a Amazônia abriga entre trezentos mil e um milhão de espécies de animais e plantas, lembrando que a maioria destas espécies existe unicamente na Amazônia e que representam recursos biológicos de suma importância para o desenvolvimento e bem-estar dos povos dos países pertencentes a esta região. $O$ fato de não podermos fixar com maior exatidão o número de espécies abrigadas pela Região Amazônica serve como denúncia de nossa ignorância quase que total sobre a vida selvagem de uma das mais ricas áreas do mundo em recursos biológicos. Mesmo em se tratando de aves, o grupo melhor conhecido, são poucos os detalhes conhecidos a respeito de distribuição, variabilidade, raças geográficas, comportamento, ecologia, reprodução e todos os outros aspectos da biologia básica da vasta maioria das espécies. Diante deste quadro de desconhecimento, como podemos enfrentar questões de espécies ameaçadas de extinção?

\section{Interdependência ecológica}

Nenhuma espécie de planta ou animal vive iso- 
ladamente; cada uma faz parte de uma comunidade de seres vivos, denominada de ecossistema. A extraordinária complexidade das interligações entre as diferentes espécies é uma das fontes principais da alta diversidade da floresta tropical ${ }^{5}$. Cada espécie de árvore, por exemplo, tem polinizador de suas flores, dispersor de seus frutos e vários predadores que comem suas folhas, o tronco ou as raízes. Imaginemos uma espécie de árvore que floresce durante um período limitado de algumas semanas do ano e tem como polinizador uma única espécie de abelha; esta árvore possui flores disponíveis durante um breve período, mas a abelha tem de se alimentar o ano todo. Sendo assim, a árvore torna-se dependente de várias outras espécies de plantas para a manutenção de seu polinizador durante boa parte do ano. A sobreposição de numerosas cadeias de relação deste tipo entre espécies cria íntimas ligações de interdependência ecológica na comunidade. A extinção de uma espécie de planta ou animal num ecossistema tropical tem potencial suficiente para desencadear uma série de extinções, devido a esta interdependência. Espécie ameaçada de extinção é um sintoma de insalubridade do ecossistema em geral ${ }^{6}$, e a identificação de uma espécie em extinção passa a ser um exercício com profundas ramificações. 0 fato de que a ararajuba (Aratinga guarouba), lindo psitacídeo que existe exclusivamente em determinadas partes florestadas dos estados do Pará e Maranhão, esteja ameaçada de extinção é um sinal de alerta para o homem da ameaça a todo o ecossistema da região. Centenas de espécies de insetos, dezenas de plantas, vários mamíferos e inúmeras outras espécies estão ameaçadas juntamente com a ararajuba. Mesmo que muitas destas espécies ainda não tenham nome científico, podemos afirmar que precisam de esforços especiais para garantir a sua sobrevivência.

Colocado sob este ponto de vista, a importância das 86 espécies da fauna indígena reconhecidas oficialmente pelo Instituto Brasileiro de Desenvolvimento Florestal - IBDF, como ameaçadas de extinção no Brasil7, fica mais significativa. A lista em sí é conservadora e exige uma revisão, mas serve como um guia preliminar para a política de conservação dos recursos biológicos do país.

A maior concentração de espécies ameaçadas de extinção da lista oficial localiza-se na Floresta Atlântica, onde a vegetação original já foi reduzida a $2 \%$ de sua extensão original ${ }^{8}$. Esta floresta, que estendia originalmente do Rio Grande do Norte a São Paulo, hospeda plantas e animais extraordinários como o muriqui (Brachyteles arachnoides), o maior primata não-humano do continente, reduzido a aproximadamente duzentos indivíduos 9 . O Sergipe pode ser, no próximo ano, o primeiro estado a extinguir completamente o seu último reduto desta flo- resta. De fato, somente a devastada Floresta Tropical da llha de Madagáscar rivaliza a Floresta Atlântica em termos do número de espécies ameaçadas. A possibilidade de perder o pouco que resta da Floresta Atlântica brasileira traz o temor de que a primeira grande onda de extinções causada diretamente pelo ser humano vai ser um feito brasileiro. A eliminação das manchas remanescentes deste riquíssimo acervo ecológico causaria literalmente a extinção de milhares de espécies exclusivas desta área. Isto representa que, recursos exclusivamente brasileiros por falta de manejo e visão, poderiam ser jogados pelos ventos, negados às gerações futuras.

A situação na Amazônia ainda não chegou a um ponto tão drástico. Mesmo assim, a metade das espécies da lista oficial do IBDF são da Amazônia, e a região ainda pode sofrer extinção de várias espécies até o fim do século. O visitante percebe a floresta como uniforme, mas a hiléia amazônica é muito diversificada e variável em termos das comunidades biológicas. As plantas e animais encontrados em florestas do alto Rio Negro são completamente diferentes daqueles do Rio Purús. A distribuição atual das espécies da Amazônia apresenta um padrão de diversidade excepcionalmente alta em determinadas regiões da bacia, que abrigam grandes números de espécies endêmicas. Temos evidências geomorfológicas que indicam que estas áreas correspondem a distritos que sempre tinham cobertura florestal ${ }^{10}$. Outras áreas da bacia mostram evidências de terem sofrido mudanças de clima durante o Pleistoceno, quando diminuíram as chuvas, devido à grande proporção da água do globo presa nas geleiras que cobriam as altas latitudes. Então, há certas áreas de florestas da Amazônia que ficavam isoladas, uma da outra, durante a época glacial. Naquele período, o cerrado e outras vegetações mais secas substituíram a floresta em muitas áreas e o conseqüente isolamento das regiões florestadas deu origem aos centros de endemismo encontrados hoje ${ }^{11}$. Como estes centros de endemismo têm concentrações excepcionais de recursos biológicos, são prioritários para reservas biológicas. De fato, o Departamento de Parques Nacionais e Reservas Equivalentes - DN, do IBDF, usa este conceito de centros de endemismo, à chamada "teoria de refúgios pleistocenos", como guia principal na localização de unidades de conservação na Amazônia ${ }^{12}$. Cada região distinta da Amazônia tem de ter suas próprias reservas. O fato de que uma boa parte da bacia do Rio Negro seja preservada em parques nacionais não diminui a urgência de indicar uma reserva substancial na região de Belém (Rio Tocantins até o oeste do Maranhão), importantíssimo centro de endemismo que hoje sofre enormes pressões de desenvolvimento.

Infelizmente, a importância de uma política conservacionista, que tenta preservar a riqueza do 
Brasil, é compreendida por poucas pessoas. Parte do problema é a dificuldade de indicar um valor econômico para cada espécie, para formular um argumento capaz de convencer os tecnocratas encarregados da política de desenvolvimento da importância da conservação. Diante dos cálculos diretos do valor de um projeto para o plantio de cana-de-açúcar, por exemplo, não entra o valor da floresta que os canaviais vão substituir. $E$, na verdade, o que valem algumas espécies de árvores, formigas, abelhas, pássaros, ratinhos, etc. em comparação à necessidade imediata de aumentar a produção de álcool? O álcool é necessário para liberar o país do constrangimento da conta do petróleo. Mas será que aquela floresta que está sendo derrubada não contém espécies selvagens com potencial de também substituir o petróleo? ou curar doenças? ou alimentar um mundo faminto? ou produzir novas fibras? ou atender inúmeras outras demandas da sociedade humana? O simples fato de que os cientistas não podem colocar um valor " $x$ " em cada espécie não é indicativo da falta da utilidade da espécie, mas, novamente, um indicativo de nossa ignorância. Jogar fora estes recursos por falta de valor contábil imediato é como jogar fora bauxita por reconhecer o seu valor unicamente em papel de alumínio.

E bom lembrar que os recursos biológicos são nos apresentados numa forma que pode ser considerada crua. Os principais cereais, por exemplo, eram meras ervas quando o ser humano começou a sua domesticação e hoje são maravilhas estocadoras de alimento, fábricas vegetais de calorias para o consumo humano. Vários outros milagres poderíamos fazer, se as espécies selvagens não fossem destruídas.

\section{Quadro atual na Amazônia}

Não deixa de ser irônico o fato de que algumas das espécies ameaçadas de extinção na Amazônia estão entre os animais e plantas mais úteis da região, por exemplo, a tartaruga (Podecnemis expansa) e o peixe-boi (Trichecus inunguis), que sustentavam as populações indígenas com proteínas de alta qualidade. ${ }^{13} \mathrm{Com}$ a chegada dos europeus começou a exploração predatória que se agravou neste século e hoje leva as espécies à beira de extinção, entre elas, o tambaqui (Colossoma macropomum) $)^{14} \mathrm{e}$ o pirarucu (Arapaima gigas) ${ }^{15}$, de suma importância, até recentemente, para o mercado de Manaus, que logo podem ter seus estoques exauridos, também vítimas por serem úteis demais. Com manejo, estes animais poderiam novamente virar fontes importantes de alimentos, se eles não desaparecessem antes. Situação semelhante tem o pau-rosa (Aniba spp. - Lauraceae), que contém um precioso óleo, o qual é cobiçado pela indústria de perfumes inter- nacional, e que nas décadas de 60 e 70 sofreu uma exploração desenfreada com a conseqüente dizimação de suas populações. O número de indivíduos que resta desta planta é tão reduzido que a espécie já é considerada "comercialmente extinta"16.

Foi o reconhecimento do desperdício da exploração sem controles que levou o governo brasileiro a promover as leis básicas de proteção da fauna e flora a partir de $1966^{17}$. Dois órgãos do governo federal atuam diretamente com a conservação da natureza: o IBDF, subordinado ao Ministério da Agricultura, cuida dos parques nacionais e reservas equivalentes, enquanto a Secretaria Especial do Meio Ambiente - SEMA, ligada ao Ministério do Interior, atua na área de estações ecológicas.

As estações ecológicas diferem dos parques nacionais, pois, além de preservação, têm como objetivo o estudo dos ambientes naturais pelas universidades e órgãos de pesquisa do país, utilizando não somente a área protegida, mas também as áreas vizinhas ocupadas pelo homem, para estudos comparativos.

Desde a sua criação, em 1973, a SEMA atua com grande êxito na demarcação e implantação das estações ecológicas ${ }^{18}$. Só na Amazônia legal existem onze estações, englobando quase 1.800 .000 hectares, em áreas da bacia, de alta importância ecológica, e encontra-se em implantação a única unidade de conservação do Estado do Acre, sob administração da SEMA: a Estação Ecológica do Rio Acre ${ }^{19}$.

O desempenho do secretário especial do Meio Ambiente, Paulo Nogueira Neto, valeu-the o "Prêmio Getty", também chamado o "Nobel de Conservação Mundial", em 1982, quando ele o dividiu com Maria Tereza Jorge Pádua, então diretora do Departamento de Parques Nacionais e Reservas Equivalentes - DN, do IBDF. O sistema de reservas decretadas e planejadas por estes dois órgãos é exemplar. Infelizmente, por absoluta falta de verba para a compra de terras, eles somente podem atuar efetivamente em terras devolutas.

Os parqueś nacionais têm crônicos problemas com falta de infra-estrutura e guardas florestais e os decretos, em si, são insuficientes para garantir a integridade dos parques e reservas equivalentes ${ }^{20}$, que têm de ser defendidos com vigor.

As leis que protegem a flora e fauna brasileiras são ótimas, mas falta fiscalização. O envolvimento da polícia federal na fiscalização do Pantanal MatoGrossense é um importante passo no controle do contrabando de peles de jacarés e onças e de animais vivos existentes na região. Por outro lado, temos a proposta de Gilberto Mestrinho, governador do Estado do Amazonas, para a liberação da caça profissional visando a exportação de peles de ani- 
mais silvestres. O Fundo Monetário Internacional FMI, na primeira carta de intenções assinada com o Brasil21 , também incluiu uma cláusula pedindo a facilitação da exportação destes produtos.

O objetivo da conservação da natureza é a poupança dos recursos naturais para garantir a sua disponibilidade no futuro e a exploração econômica destes recursos é sempre admitida, uma vez que tal exploração seja efetuada com conceitos de manejo responsável. Atualmente não existem mínimas condições para o manejo dos animais que o sr. Mestrinho propõe abater. As informações básicas dos estoques disponíveis, a taxa de recomposição das populações, o período reprodutivo e as demais informações que precisamos para manejar as espécies, são desconhecidas. Se a proposta do governador leva os órgãos competentes a iniciarem os estudos necessários para o manejo destes recursos, ele teria prestado grande serviço à nação.

A estrutura atual da administração dos recursos biológicos do Brasil ainda pode ser melhorada. A proposta elaborada por uma força-tarefa da Organização das Nações Unidas - ONU para a criação de um "Ministério de Recursos Naturais Renováveis" 22 tem muito a se recomendar. Tal reestruturação faria muito mais eficaz a organização do manejo dos recursos biológicos do Brasil e mostraria a seriedade com que o governo trata a ameaça ao "capital biológico" do país. Um levantamento geral dos recursos biológicos do país é recomendável como primeiro passo à integração destes recursos aos programas de desenvolvimento. $\mathrm{O}$ fato de o país enfrentar grande crise econômica não deve ser usado para justificar o adiamento deste programa, devendose levar em consideração que os recursos biológicos são uma das dádivas mais importantes e valiosas do Brasil, e o desperdício desses recursos equivale-se à queima de livros. Ruimé que muitos destes "livros" ainda não estão escritos; e o que é pior é que, além de não estarem escritos, eles contêm os segredos da estabilidade e prosperidade dos brasileiros para o futuro. O manejo responsável destes recursos encaminhará o Brasil à posição certa e natural do país mais rico em capital biológico do mundo.

\section{Referências Bibliográficas}

1. LOVEJOY, T.E. The problem of species extinction: the global 2000 report to the president. Washington, Council on Environmental Quality, 1981.
2. BARNES, R.D. Invertebrate zoology. Philadelphia, W.B. Saunders and Company, 1968.

3. AMADON, D. Birds of the Congo and Amazon forests; a comparison. In: MEGGERS, B.J. et alii ed. Tropical forest ecosystems in Africa and South America: a comparative review. Washington, District of Columbia. Smithsonian Institution Press, 1973.

4. WELTY, J.C. The life of birds. Philadelphia, W.B. Saunders and Company, 1975.

5. MacARTHUR, R.H. Geographical ecology; patterns in the distribution of species. New York, Harper and Row, 1972.

6. LOVEJOY, T.E. op. cit.

7. IBDF. Portaria N. 303 de 29/5/68 (treze espécies de plantas), e IBDF. Portaria No 3.481 de $31 / 5 / 73$ (86 espécies de animais).

8. CÂMARA I. de Gusmão. In: CONGRESSO BRASILEIRO DE ZOOLOGIA, 10. Belo Horizonte, 1983.

9. MITTERMEIER, R. In: CONGRESSO BRASILEIRO DE ZOOLOGIA, 10. Belo Horizonte, 1983.

10. AB'SABER, A.N. Espaços ocupados pela expansão dos climas secos na América do Sul, por ocasião dos períodos glaciais quaternários. São Paulo, Paleoclimas, 3, 1977.

11. HAFFER, J. Avian speciation in South America. Cambridge, Nuttall Ornithological Club, 1974

12. PÁDUA, M.T.J. et alii. Plano do sistema de unidades de conservação do Brasil;segunda etapa. Brasília, MAIIBDFFBCN, 1982.

13. AYRES, J.M. \& BEST, R. Estratégias para a conservação da fauna amazônica. Manaus, Acta Amazonia, 9 (4 supl.), 1979.

14. GOULDING, M. \& CARVALHO, M.L. Life history and management of the tambaqui (Colossoma macropomum, Characidae); an important Amazonian food fish. Revista Brasileira de Zoologia, 1 (2): 107-33, 1983.

15. SMITH, N.J.H. Man, fishes, and the Amazon. New York, Columbia University Press, 1981

16. PIRES, J.M. In: SIMPOSIO INTERNACIONAL SOBRE A AMA ZÓNIA, 35. REUNIÃO DA SOCIEDADE BRASILEIRAPARA O PROGRESSO DA CIENCIA. Belém, 1983.

17. CAVALCANTI, DF. Legislação de Conservação da Natureza. Rio de Janeiro, FBCN, 1971.

18. Decreto $n^{\circ} 73.030$ de $30 / 10 / 73$.

19. Decreto n. 86.061 de $2 / 6 / 81$.

20. PADUA, M.T.J. In: SIMPOSIO INTERNACIONAL SOBRE A AMAZŌNIA, 35. REUNIÃO DA SOCIEDADE BRASILEIRA PARA O PROGRESSO DA CIENCIA. Belém, 1983

21. Item 26, FUNDO MONETARIO INTERNACIONAL. Carta de Intenções, e item 6. FUNDO MONETÁRIOINTERNACIO $\mathrm{NAL}$, Memorando de entendimento.

22. CASTRO, J.H.F. Alguns aspectos do problema brasileiro. Relatório Técnico 19, IBDFMA/FAO/ONU, Brasilia, 1982. 